World Applied Sciences Journal 5 (3): 302-310, 2008

ISSN 1818-4952

(C) IDOSI Publications, 2008

\title{
Generation Reliability Assessment in Power Markets Using Monte Carlo Simulation and Intelligent Systems
}

\author{
${ }^{1}$ H. Haroonabadi and ${ }^{2}$ M.R.. Haghifam \\ ${ }^{1}$ Electrical Department, Islamic Azad University - \\ Science and Research Branch, P.O. Box 14515/775, Tehran, Iran \\ ${ }^{2}$ Department of Electrical and Computer, Tarbiat Modarres University, P.O. Box 14115-349, Tehran, Iran
}

\begin{abstract}
Deregulation policy has caused some changes in the concepts of power systems reliability assessment and enhancement. In this paper, generation reliability is considered and a method for its assessment using intelligent systems is proposed. Also, because of power market and generators' forced outages stochastic behavior, Monte Carlo Simulation is used for reliability evaluation. Generation reliability, merely focuses on interaction between generation complex and load. Therefore, in this research, based on market type and its concentration, reserve margin and various future times, a Neuro-Fuzzy system is proposed for evaluation of generation reliability which is valid and usable for all kinds of power pool markets. Finally, the proposed method is assessed on IEEE-Reliability Test System with satisfactory results. It will be shown that if market becomes more concentrated or price elasticity of demand increases, reliability will improve.
\end{abstract}

Key words : Generation reliability. Power pool market. Monte carlo simulation. Intelligent systems

\section{INTRODUCTION}

Power systems have evolved over decades. Their primary emphasis has been on providing a reliable and economic supply of electrical energy to their customers [1]. A real power system is complex, highly integrated and almost very large. It can be divided into appropriate subsystems or functional zones that can be analyzed separately [2]. This paper deals with generation reliability assessment (HLI) in power pool market and transmission and distribution systems are considered reliable and adequate as shown in Fig. 1.

Most of the methods used for HLI reliability evaluation, are based on the "loss of load or energy" approach. One of the suitable indices that describes generation reliability level is Loss Of Load Expectation (LOLE); that is the time in which load is more than available generation.

Generally, the reliability indices of a system can be evaluated using one of two basic approaches [3]:

- Analytical techniques.

- Stochastic simulation.

Simulation techniques, estimate the reliability indices by simulating the actual process and random behavior of the system. Since power markets and

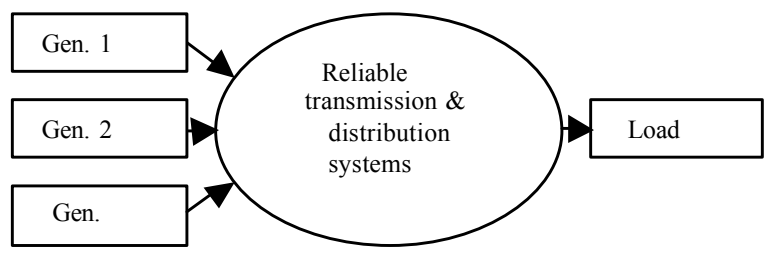

Fig. 1: Power pool market schematic for HLI reliability assessment

generators' forced outages have stochastic behavior, Monte Carlo Simulation (MCS) which is one of the most powerful methods for statistical analysis of stochastic problems, is used for reliability assessment in this research.

HLI reliability depends absolutely on generating units specifications. The main function in traditional structure for Unit Commitment (UC) of generating units is generation cost minimization. Since beginning $21^{\text {st }}$ century, many countries have been trying to deregulate their power systems and create power markets [4-8]. In power markets, the main function of players, is their own profit maximization; which severely depends on type of the market. As a result, reliability assessment in HLI completely depends on market type and its characteristics.

Corresponding Author: Dr. H. Haroonabadi, Electrical Department, Islamic Azad University - Science and Research Branch, P.O. Box 14515/775, Tehran, Iran 
Generally, economists divide the markets in four groups which vary between perfect competition market and monopoly market [9]. This study deals with evaluation of generation reliability in different kinds of power pool markets based on characteristics of demand.

In [10], independent power producers' impact on reliability and associated costs of existing power systems under deregulation environment has been presented. This paper has used "Expected Unserved Power" (EUP) as reliability index and economic dispatch problem is solved under some reliability and system constraints.

Reference [11] has used "Effective Load Duration Curve" (ELDC) for evaluation of "Loss Of Load Expectation" (LOLE) and "Expected Energy Not Served" $(E E N S)$ as reliability indices in HLI.

Reference [12] has presented some reliability models for different players in a power system. Generation system is represented by an equivalent multi-state generation provider (EMGP). The reliability parameters of each $E M G P$ are shown by an available capacity probability table $(A C P T)$ which is determined using conventional techniques. Then, the equivalent reliability parameters for each state (including state probability, frequency of encountering the state and the equivalent available generation capacity) are determined.

Reference [13] has presented generation operational cost minimization problem under system constrains and load uncertainty for evaluation of "Expected Unserved Power" (EUP) as reliability index.

In many papers deal with power marketing and restructuring, market behavior and its economic effects on the power system is ignored. Therefore, this paper meantime to consider power pool market fundamentals, deals with HLI reliability assessment in power pool market using MCS and a Neuro-Fuzzy system. Also, sensitivity of reliability index to different reserve margins and times will be evaluated. In section-II fundamental of power pool market is discussed. In section-III, the algorithm for HLI reliability assessment in power pool market will be proposed and finally in section-IV case study results are presented and discussed.

\section{POWER POOL MARKET FUNDAMENTALS}

Market demand curve has negative gradient. Amount of demand decrease is explained by "price elasticity of demand". This index is small for short terms and big for long terms; because in longer terms, customers can better adjust their load relative to price [14]. Demand function, generally, is described as $P=a-b . Q$. Therefore, price elasticity of demand is explained as (1):

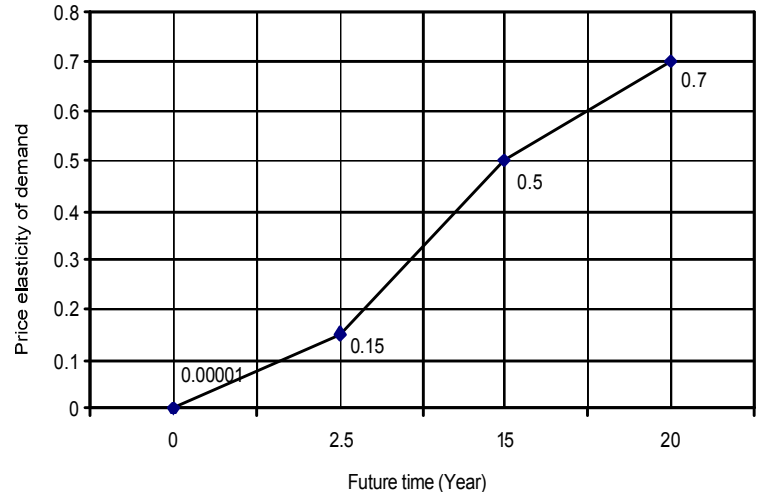

Fig. 2: Price elasticity of demand for various times

$$
\mathrm{E}_{\mathrm{d}}=\left|\frac{\mathrm{dQ}}{\mathrm{dP}}\right|=\frac{1}{\mathrm{~b}}
$$

Let's suppose forecasted load by dispatching and control centers is an independent power from price and it equals $Q_{n}$. Therefore, price of electrical energy is zero. As a result, demand function can be obtained as (2).

$$
P=a-b \cdot Q=b \cdot Q_{n}-b \cdot Q=\frac{Q_{n}}{E_{d}}-\frac{Q}{E_{d}}
$$

Typically as shown in Fig. 2, price elasticity in power markets, is $0.1-0.2$ for 2-3 future years and 0.30.7 for 10-20 future years [14]. In short terms, costumers can't completely adjust their consumption with price and price elasticity is small and in long terms it is high.

Offer curve of a company which participates in a market without any market power, is the part of marginal cost curve that is more than minimum average variable cost [9]. Also, total offer curve of all companies, is obtained from horizontal sum of each company's offer curve. This curve is a price increase step or merit order function. In economics, if sale price in a market becomes less than minimum average variable cost, the company will stop production; because the company will not cover variable cost in addition to fixed cost [9]. Because of changing efficiency and heat rate in power plants, marginal cost becomes less than average variable cost. Therefore, in power plants, average variable cost replaces marginal cost [15].

In a perfect competition market, equilibrium price and equilibrium amount are obtained from intersection of total offer curve and demand curve. On the other hand, in a monopoly market, the monopolist considers the production level which maximizes his profit. It is proved that monopolist considers the level of 


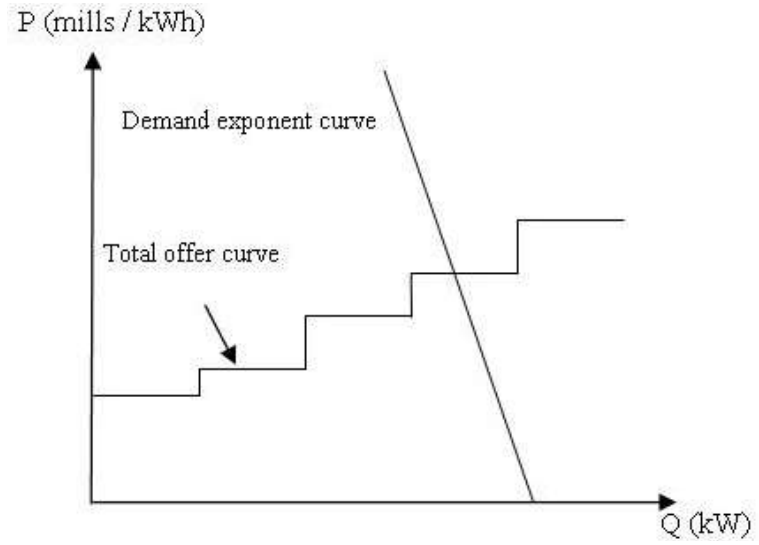

Fig. 3: Typical total offer and demand exponent curves

production in which marginal cost of each firm (and total marginal cost of all firms) equals he marginal revenue of the monopolist [9].

$$
\mathrm{MC}_{1}=\mathrm{MC}_{2}=\ldots=\mathrm{MC}=\mathrm{MR}
$$

Where:

$$
M R=a-2 \cdot b \cdot Q=b \cdot Q_{n}-2 \cdot b \cdot Q=\frac{Q_{n}}{E_{d}}-\frac{2 \cdot Q}{E_{d}}
$$

Comparison (2) and (4) produces a result that if there is no any market power, offer curve of industry for each market (from perfect competition to monopoly) will equal marginal cost; but negative gradient of demand exponent curve $(D E)$ varies between $b$ (for demand function in perfect competition market) and $2 b$ (for marginal revenue in monopoly market). Therefore generally, demand exponent curve can be expressed as (5); where $K$ varies between 1 and 2 .

$$
\mathrm{DE}=\mathrm{a}-\mathrm{K} \cdot \mathrm{b} \cdot \mathrm{Q}=\frac{\mathrm{Q}_{\mathrm{n}}}{\mathrm{E}_{\mathrm{d}}}-\frac{\mathrm{K} \cdot \mathrm{Q}}{\mathrm{E}_{\mathrm{d}}}
$$

A typical total offer curve and demand exponent curve is shown in Fig. 3.

\section{PROPOSED METHOD FOR HLI RELIABILITY EVALUATION IN POWER MARKET}

In power markets, Hirschman-Herfindahl Index $(H H I)$ which is obtained from (6), is used for market concentration measurement [16]:

$$
\mathrm{HHI}=\sum_{\mathrm{M}} \mathrm{q}_{\mathrm{i}}^{2}
$$

If market shares are measured in percentages, $\mathrm{HHI}$ will vary between 0 (an atomistic market) and 10000

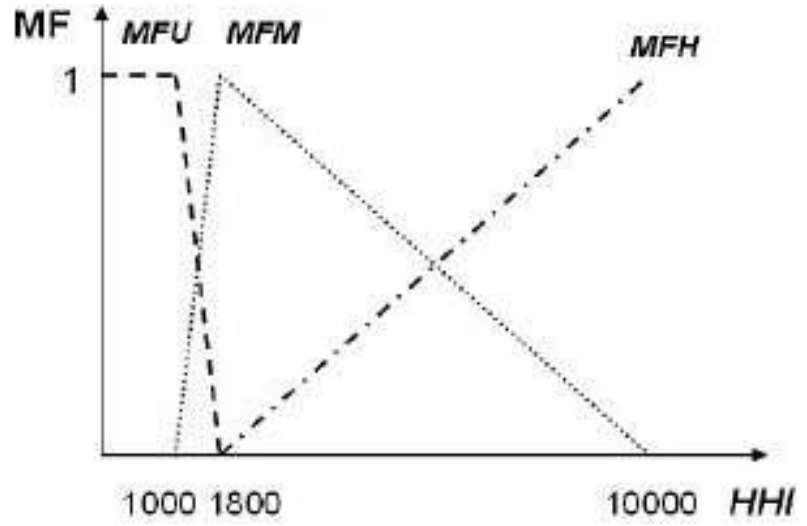

Fig. 4: Membership functions of unconcentrated, moderately concentrated and highly concentrated markets fuzzy sets

(monopoly). In one usual grouping, the US merger guidelines stipulates an assumption that markets with a HHI below 1000 is unconcentrated, a $H H I$ between 1000 and 1800 is moderately concentrate and a $H H I$ above 1800 is highly concentrated [17].

As mentioned before, according to type of market and $H H I$ value, negative gradient of demand exponent curve, varies between $b$ and $2 b$. Therefore in this paper, for modeling the market, a fuzzy number is proposed for estimate of demand exponent curve gradient coefficient $(K)$ based on $H H I$ values. Membership functions of unconcentrated, moderately concentrated and highly concentrated markets fuzzy sets and the equation to estimate gradient coefficient are shown in Fig. 4 and 7, respectively.

$$
\mathrm{K}=(\mathrm{MFU}+1.5 \times \mathrm{MFM}+2 \times \mathrm{MFH})
$$

As can be seen from Fig. 4 and 7, while proposed coefficient $(K)$ covers all kinds of markets with different degrees, at the same time, the change of degrees is not sudden, rather it is gradual and continuous. Also, the proposed method and fuzzy logic are valid for all power pool markets.

Generation reliability of a power system depends on many parameters. One of these parameters which has an important role, is reserve margin which is defined as (8) [18].

$$
\mathrm{RM} \%=\frac{\text { Installed } \quad \text { Capacity }- \text { Peak } \quad \text { Demand }}{\text { Peak Demand }} \times 100
$$

Algorithm of HLI reliability assessment in power pool markets using Monte Carlo simulation is shown in Fig. 5. Steps of proposed algorithm are as following: 


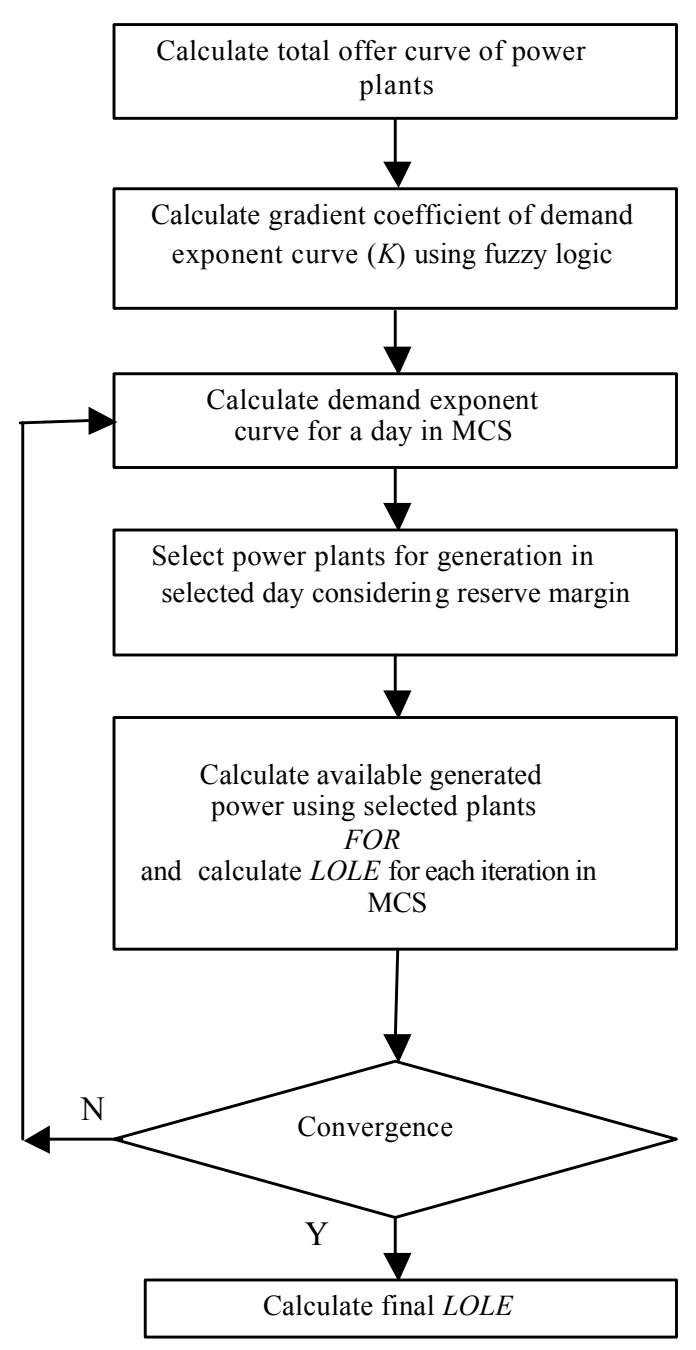

Fig. 5: Flow chart of HLI reliability assessment in power markets using MCS

- $\quad$ Based on characteristic of market, $H H I$ is obtained. Using Fig. 4 and 7, gradient coefficient of demand exponent curve $(K)$ is calculated.

- Calculation of total offer curve of power plants.

- Determinations of the day and related load $\left(Q_{n}\right)$ randomly and demand exponent curve using (5).

- The power plants which are selected for generation in the selected day are determined from intersection of power plants' total offer curve and demand exponent curve with regards to reserve margin.

- $\quad$ For each selected power plant in previous step, a random number between [0-1] is generated. If the generated number is more than power plant's FOR, the power plant is considered available in mentioned iteration; otherwise it encounters forced outage and can't generate power. This process is

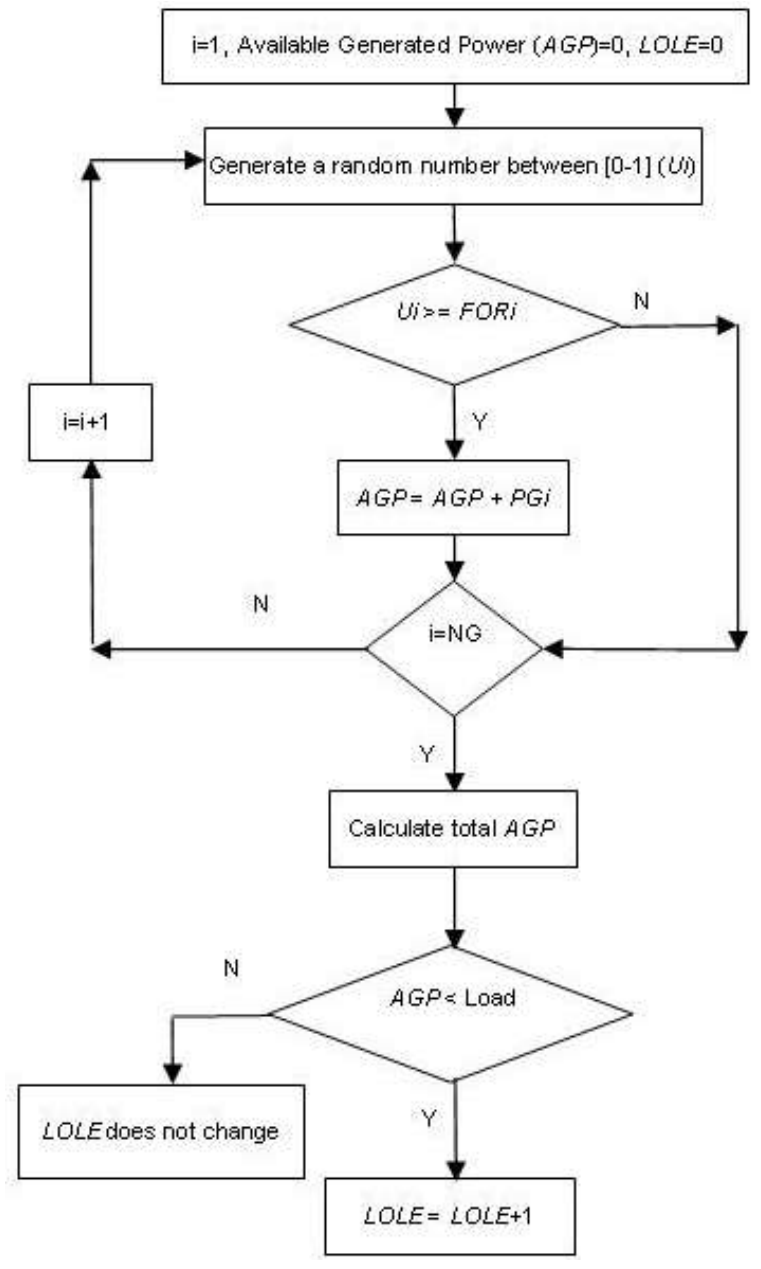

Fig. 6: Algorithm of available generated power and $L O L E$ calculations for each iteration using MCS

performed for all power plants using an independent random number generated for each one of them. Finally, sum of the available power plants' generations is calculated. If the sum becomes less than intersection of power plants' total offer curve and demand exponent curve, we will have interruption in the iteration and therefore, $L O L E$ increases one unit; otherwise, we go to the next iteration. Algorithm of available generated power and $L O L E$ calculations for each iteration in MCS is shown in Fig. 6.

- $\quad$ Steps 3 to 5 are repeated for calculation of $L O L E$.

Now, for creating a unique structure, a four layers perceptron neural network (N.N.) is used for reliability evaluation. Number of neurons in each layer is 20, 15, 12 and 1, respectively as shown in Fig. 7. All neurons in first, third and last layers have POSLIN transfer function and second layer has TANSIG transfer 


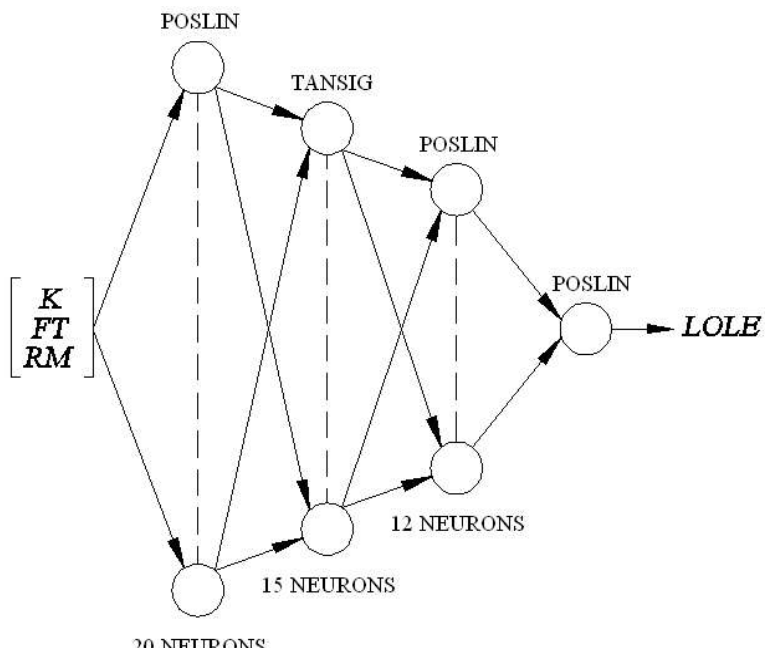

Fig. 7: Proposed N.N. for HLI reliability evaluation

function. Input of the neural network includes coefficient of demand exponent curve gradient $(K)$, simulated future time $(F T)$ and reserve margin $(R M)$; and its output is $L O L E$ index. Some of the MCS results which obtained using mentioned algorithm are used for neural network training.

\section{NUMERICAL STUDIES}

IEEE-Reliability Test System (IEEE-RTS) is used for case studies. Data for IEEE-RTS can be found in [19]. In various case studies following assumptions are applied:

- All studies are simulated for second half year, based on daily peak load of mentioned test system.

- All simulations are done with 5000 iterations.

- Neural network is trained with TRAINLM method in MATLAB 7.0 software with 150 epochs and finds 0.2 Mean Square Error (MSE).

- Each study is simulated for two different times (present time and $2^{\text {nd }}$ future year) and with two different reserve margins $(0 \%, 9 \%)$.

- Annual growth rates of power plants' generation capacity and consumed load are considered 3.4\% and $3.34 \%$ respectively.

- Annual growth rates of oil and coal costs are considered $4 \%$ and $1 \%$ respectively. Nuclear fuel cost (including uranium, enrichment and fabrication) is considered as a fixed rate. Also, annual growth rate of variable O\&M cost is considered $1 \%$.

In first study, each power plant is assumed as an independent company. Therefore, $H H I$ equals 634 and

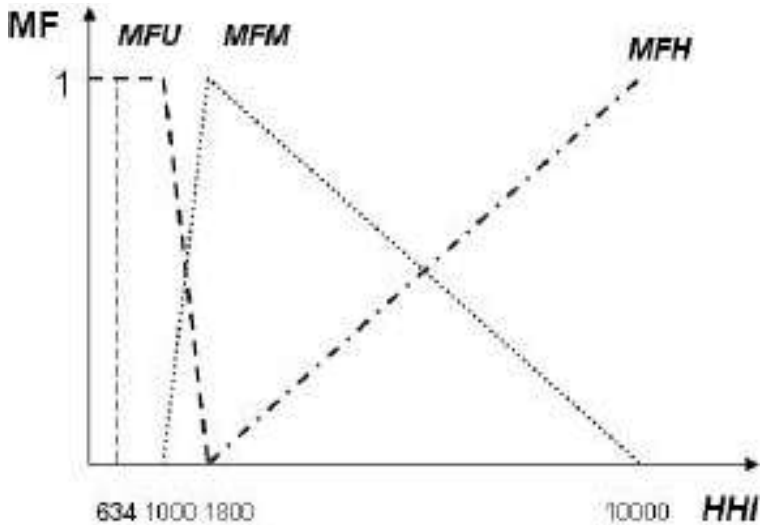

Fig. 8: Demand exponent curve gradient calculation using membership functions for first study

$\mathrm{HHI}=634 \& \mathrm{~K}=1$

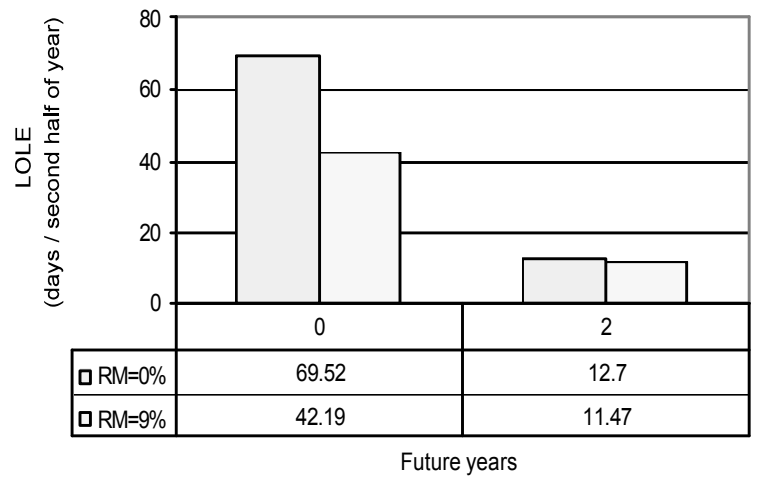

Fig. 9: $L O L E$ values for first study using MCS

$H H I=634 \& K=1$

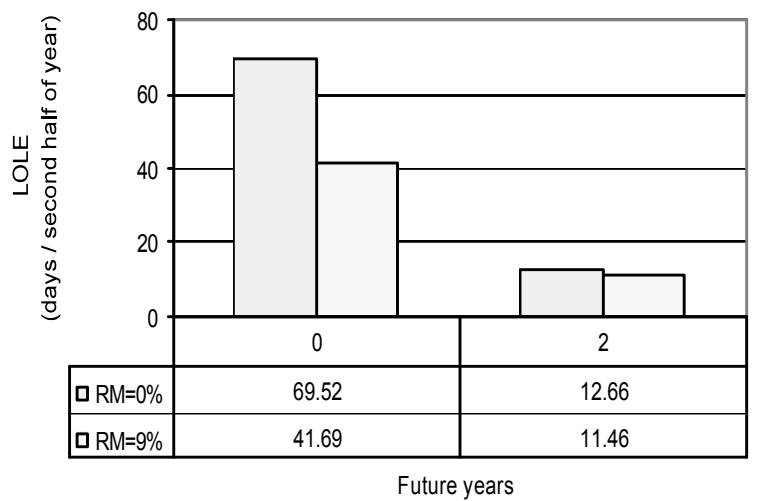

Fig. 10: $L O L E$ values for first study using N.N

the market will be unconcentrated. Using Fig. 4 and 7, $K$ is calculated 1 as shown in Fig. 8. Based on this assumption and using MCS algorithm and proposed neural network, LOLE values are obtained versus 


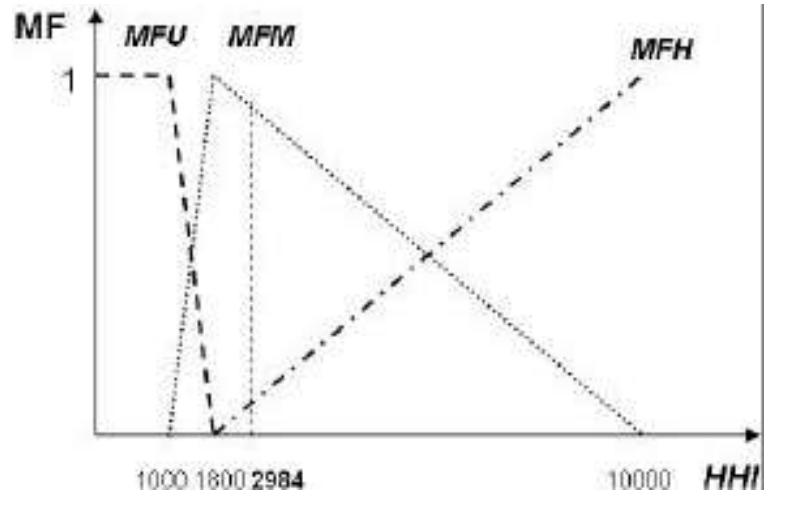

Fig. 11: Demand exponent curve gradient calculation using membership functions for second study

$H H I=2984 \& K=1.5722$

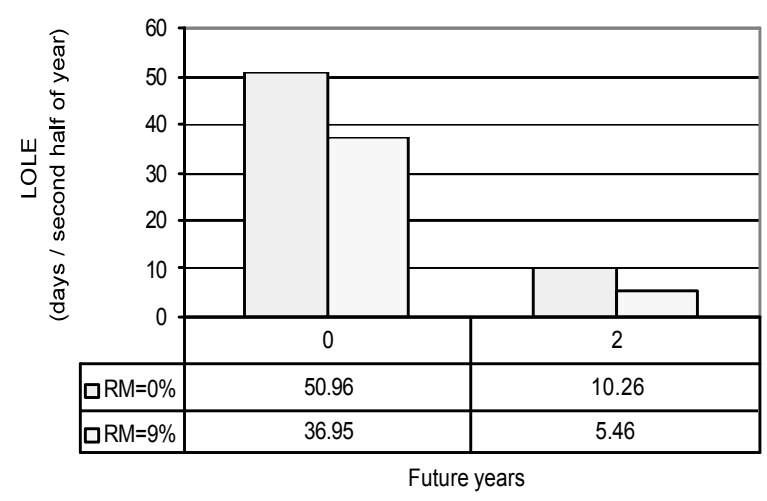

Fig. 12: $L O L E$ values for second study using MCS

$H H I=2984 \&$ K=1.5722

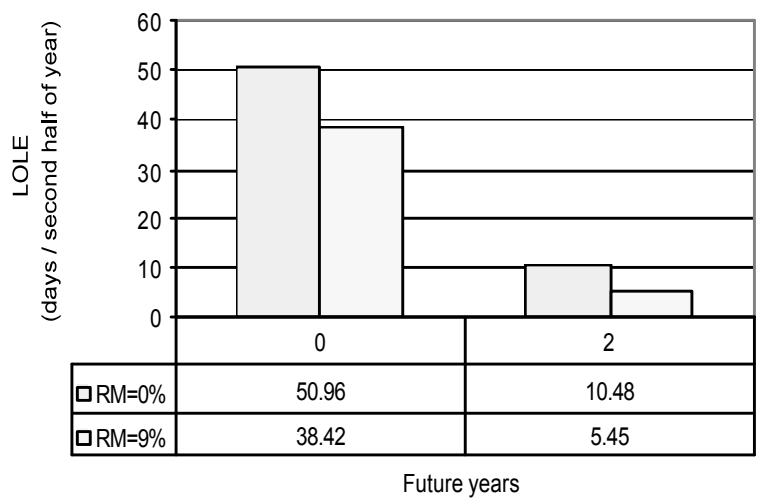

Fig. 13: $L O L E$ values for second study using N.N.

different times and reserve margins as shown in Fig. 9 and 10 , respectively.

The error between $L O L E$ values in MCS and neural network results in percentage of MCS results in first study is $0.4 \%$.

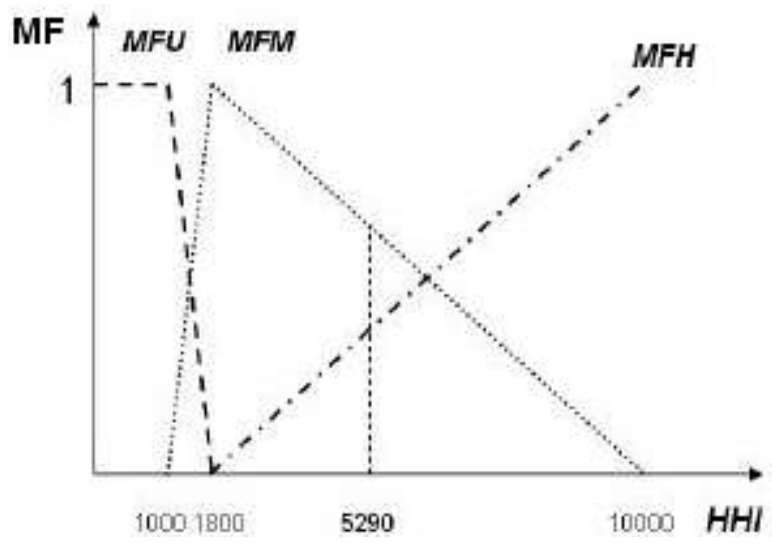

Fig. 14: Demand exponent curve gradient calculation using membership functions for third study

$H H I=5290 \& K=1.7128$

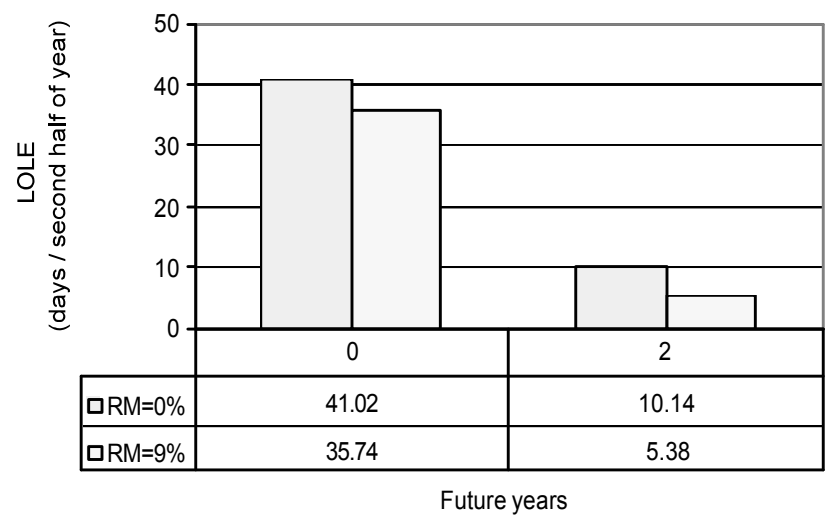

Fig. 15: $L O L E$ values for third study using MCS

In second study, all power plants based on their types (including: oil, coal, nuclear and water plants), are classified. Therefore, $H H I$ equals 2984 and $K$ is calculated 1.5722 as shown in Fig. 11. Based on this assumption and using MCS algorithm and proposed neural network, LOLE values are obtained versus different times and reserve margins as shown in Fig. 12 and 13 , respectively.

The error between LOLE values in MCS and neural network results in percentage of MCS results in second study is $1.64 \%$.

In third study, all fossil power plants (including oil and coal power plants), are classified in one company and others are as second case study. Therefore, types of power plants are fossil, nuclear and water. As a result, $H H I$ equals 5290 and $K$ is calculated 1.7128 as shown in Fig. 14. Based on this assumption and using MCS algorithm and proposed neural network, LOLE values are obtained versus different times and reserve margins as shown in Fig. 15 and 16, respectively. 
$\mathrm{HHI}=5290 \& \mathrm{~K}=1.7128$

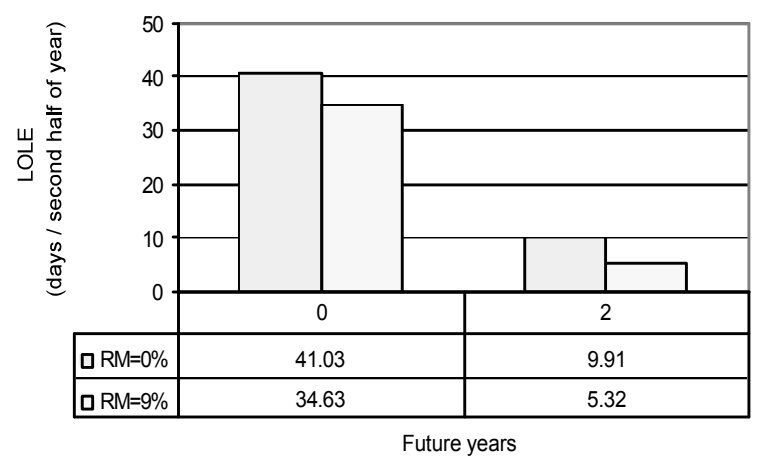

Fig. 16: $L O L E$ values for third study using N.N.

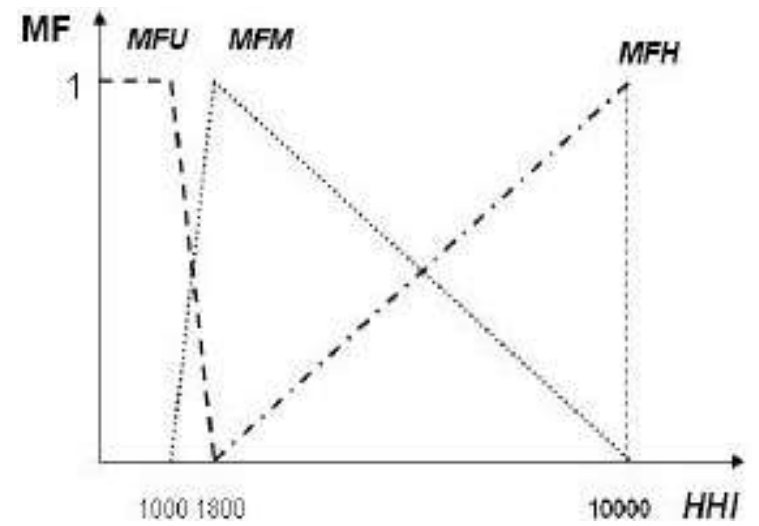

Fig. 17: Demand exponent curve gradient calculation using membership functions for forth study

The error between $L O L E$ values in MCS and neural network results in percentage of MCS results in third study is $1.53 \%$.

In fourth and last study, it is assumed that all power plants belong to a monopolist and the market will be fully concentrated and monopoly. Therefore, HHI equals 10000 and $K$ is calculated 2 as shown in Fig. 17. Based on this assumption and using MCS algorithm and proposed neural network, LOLE values are obtained versus different times and reserve margins as shown in Fig. 18 and 19, respectively.

The error between $L O L E$ values in MCS and neural network results in percentage of MCS results in forth study is $0.5 \%$.

As it's remarkable, $L O L E$ values in neural network method are very similar to MCS values.

In all case studies, if reserve margin increases $L O L E$ will decrease and reliability will improve.

As mentioned before, in longer terms, customers can better adjust their load relative to price. Therefore, price elasticity increases and according to (5), demand exponent curve finds less gradient. As a result,
$\mathrm{HHI}=10000 \& \mathrm{~K}=2$

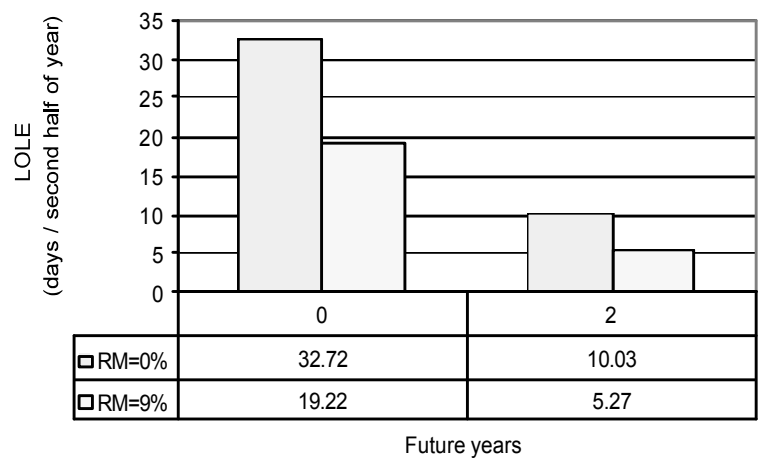

Fig. 18: $L O L E$ values for fourth study using MCS

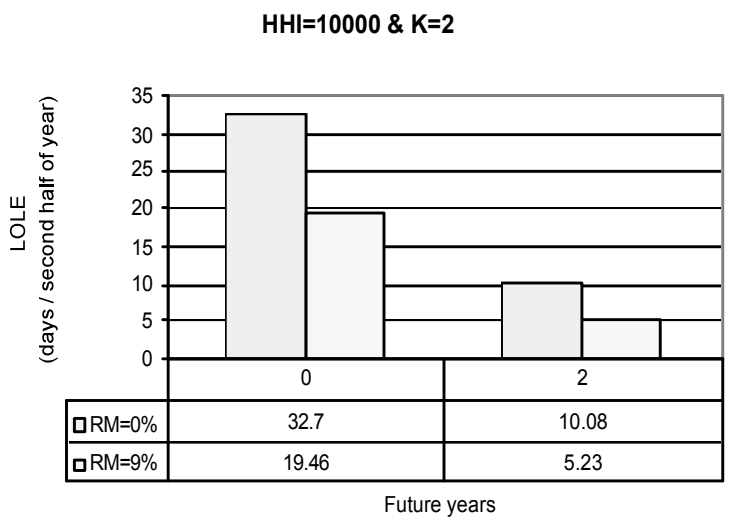

Fig. 19: $L O L E$ values for fourth study using N.N.

intersection of power plants' total offer curve and demand exponent curve occurs at less demand. This matter, leads to operate from fewer power plants. Therefore, in each study, if time increases, LOLE will decrease. Although, the annual growth rate of power plants' capacity has its effect, too.

As it's remarkable, if market becomes more concentrated or $H H I$ becomes bigger, $K$ will find bigger value, too. Therefore, according to (5), intersection of power plants' total offer curve and demand exponent curve occurs at less demand and $L O L E$ decreases. So that in the last study (monopoly market), LOLE has its least values between all studies.

It is to be noted that since in IEEE-RTS available capacity of hydro plants are different in first and second half of year, therefore simulations have been done for second half of year. Evidently, the proposed method can be utilized for every simulation time. Also, in this paper, it is supposed that annual additional generation capacity, distributes between all present generators, uniformly. If in a power system, generation planning scenarios are specified, they can be used in the proposed method. 


\section{CONCLUSION}

This paper deals with HLI reliability assessment in power pool market using Monte Carlo simulation and intelligent systems. Since changes of market concentration in power markets are gradual, a fuzzy logic is proposed for calculate gradient coefficient of demand exponent curve. Because of market and generators' FOR stochastic behavior, MCS is used for simulations. Also, for creation a unique structure for reliability assessment, a neural network is used; which its outputs are very similar to MCS results. In this research, $L O L E$ is used as reliability index and following main results are obtained:

- If market becomes more concentrated, $L O L E$ will decrease and reliability will improve.

- Whatever price elasticity of demand increases, $L O L E$ will decrease.

\section{Symbol list}

MC: $\quad$ Marginal cost (mills/kWh)

MR: Marginal revenue (mills/kWh)

Q: $\quad$ Quantity of power $(\mathrm{kW})$

P: $\quad$ Electrical energy price (mills/kWh)

RM: Reserve margin (\%)

$\mathrm{E}_{\mathrm{d}}$ : $\quad$ Price elasticity of demand $\left(\mathrm{kW}^{2} \mathrm{~h} / \mathrm{mills}\right)$

$\mathrm{Q}_{\mathrm{n}}$ : $\quad$ Forecasted load (kW)

LOLE: Loss of load expectation (days/second half year)

FOR: Forced outage rate of power plants

$\mathrm{q}_{\mathrm{i}}$ : $\quad$ Share of $\mathrm{i}^{\text {th }}$ company in the pool market (\%)

M: Number of independent companies in the market

a: Demand exponent curve cross of basis (mills/kWh)

b: $\quad$ Demand exponent curve gradient (mills $/ \mathrm{kW}^{2} \mathrm{~h}$ )

HHI: Hirschman-Herfindahl index

DE: Demand exponent curve

K: $\quad$ Gradient coefficient of demand exponent curve

MFU: Membership function of unconcentrated market

MFM: Membership function of moderately concentrated market

MFH: Membership function of highly concentrated market

FT: $\quad$ Simulated future time (year)

NG: Number of selected plants for generation in the market

AGP: Available generated power

\section{REFERENCES}

1. Billinton, R. and R. Allan, 1996. Reliability Evaluation of Power Systems, 2nd Edn. New York: Plenum press, pp: 1.
2. Billinton, R. and R. Allan, 1996. Reliability Evaluation of Power Systems. Second Edition. New York: Plenum Press, pp: 10.

3. Billinton, R. and R. Allan, 1992. Reliability Evaluation of Engineering Systems. $2^{\text {nd }}$ Edn. New York: Plenum Press, pp: 372.

4. Energy Information Administration (EIA), 1996. The changing structure of the electric power industry: An update, DOE/EIA-0562 (96). Washington DC.

5. Energy Information Administration (EIA), 1996. Electric sales and revenue, DOE/EIA-0450 (96). Washington DC.

6. Office of Gas and Electricity Market (OFGEM), 2000. Department of Trade and Industry (DTI). An overview of the New Electricity Trading Arrangement (NETA), England, Vol: 1.

7. Office of Gas and Electricity Market (OFGEM), 2001. DTI, News release, New electricity market goes live. England.

8. http:/www.ks.dk/publikationer/konkurrence/ 2003/ nordisk.

9. Robert S. Pindyck and D.L. Rubinfeld, 2001. Microeconomics. 5th Edn., USA: Prentice Hall.

10. Okada, K., H. Asano, R. Yokoyama and T. Niimura, 1999. Reliability-based impact analysis of independent power producers fr power system operations under deregulation. Proc. IEEE Canadian conference on electrical and computer engineering, pp: 1325-1330.

11. Jaeseok Choi, Hongsik Kim, Junmin Cha and Roy Billinton, 2001. Nodal probabilistic congestion and reliability evaluations of a transmission system under the deregulated electricity market. IEEE Power Engineering Society Summer Meeting, pp: 497-502.

12. Peng Wang and R. Billinton, 2003. Implementation of non-uniform reliability in a deregulated power market. IEE Proc.-Gener. Transm. Distrib., 150 (5): 857-861.

13. Satoru Niioka, Akira Kozu, Masachika Ishimaru and Ryuichi Yokoyama, 2002. Supply reliability evaluation method for deregulated electric power market considering customers uncertainty. Proc. IEEE International conference on power system technology, Proceedings PowerCon, 3: 1782-1786.

14. International Energy Agency (IEA), 2003. The power to choose-demand response in liberalized electricity markets. France: IEA, pp: 21.

15. Severin Borenstein, 1999. Understanding competitive pricing and market power in wholesale electricity market. University of California energy institute. 
16. International Energy Agency (IEA), 2003. The power to choose-demand response in liberalized electricity markets. France: IEA, pp: 54.

17. http://www.ks.dk/publikationer/konkurrence/2003/ nordisk/kap03.

18. International Energy Agency (IEA), 2002. Security of supply in electricity markets-evidence and policy issues. France: IEA, pp: 16.
19. Reliability Test System Task Force of The IEEE Subcommittee on the application of probability Methods, IEEE Reliability Test System. IEEE Transactions, Pas-98, No.6, Nov/Dec 1979, pp: 2047-2054. 